\title{
Smart Mine Construction based on Knowledge Engineering and Internet of Things
}

\author{
Xiaosan Ge*, Shuai Su, Haiyang Yu, Gang Chen, and Xiaoping $\mathrm{Lu}$ \\ Key Laboratory of Mine Spatial Information Technologies of NASG, Henan polytechnic University, Jiaozuo, 454000, China
}

\begin{abstract}
In comparison with digital mine project, the proposal of Smart Project means a difference tendency in mine informationization. From the point view of intelligent mining production process and fine mining production management, this paper firstly presented the idea of Smart Mine, based on the philosophy of a fusion of object wisdom and tool wisdom, and analyzed the connotation of Smart Mine. Then, based on a depth study of the support of knowledge engineering and the networking of things technology for Smart Mine construction, we proposed an advanced architecture of Smart Mine based on these two major technologies, and also gave a comprehensive explanation to the balance between human, environment and sustainable mineral resource exploitation in the aspects of material flow, information flow support network, the synchronization and intelligence of smart mining production process.
\end{abstract}

Keywords: smart mine; knowledge engineering; the network of things

(Submitted on February 2, 2018; Revised on March 5, 2018; Accepted on April 13, 2018)

(C) 2018 Totem Publisher, Inc. All rights reserved.

\section{Introduction}

Entering the 21st century, the rising demand of mineral resources has been bringing great pressure to social development and environmental protection $[2,9,18]$. The engineering disasters and environmental damages, induced by the large-scale exploitation of mineral resources, leads to a series of ecological damage problems such as land damage [23], shallow water level decline and water quality deterioration [17,21], solid waste pollution [10], air pollution [20], green space reduction and residential environmental degradation [1], etc. . It also threatens the human's life and property, and restricts the sustainable socio-economic development.

Early November 2008, IBM CEO Samuel Parmesan made a speech titled "A Smarter Planet: The Next Leadership Agenda" and officially put forward the concept of "smarter planet". February 2009, the IBM forum further promoted this innovative concept with the theme of "construct a smarter planet and smarter China" in Beijing, which caused wide attention of all social sectors.

The concept of "smarter planet "or "smart engineering" refers to making full use of the new generation internet technology for all walks of life, embedding in or equipping with sensors in various facilities at any sites, forming the internet of things by interconnecting each interested object. Based on supercomputers and cloud computing, it makes humans manage production and life with a more sophisticated, dynamic way, which enhances the "intelligence level" of our life around the world.

Currently, "smarter planet" (or "smart engineering") represented by "smart city" and "smart traffic" has made a great impact in many ways $[15,16,33]$. All these solutions, in response to the economic crisis, environmental degradation, are to help people manage production and life more delicately and dynamically [4,5], improve efficiency and productivity of industry resources [13,31], and ultimately to create a "smarter planet" by emphasizing future mine development on 
intellectualized mineral production management and sustainable energy development. So, what problems "smart engineering" can solve caused by mineral resource exploitation, what impact it has affected on mineral resources production and information construction, and how mining production enterprises seize the strategic opportunity to achieve new development, these issues are worth our serious consideration and further study. This paper seeks to boost Smart Mine researches by giving an overview of essential challenges and existing studies, proposing an advanced framework based on Knowledge Engineering and the Internet of Things, and suggesting possible future research trends.

\section{Background of Smart Mine Construction}

Appling with a low efficiency and high consumption development model, traditional mining enterprises pursue "maximum economic value". The environment problems caused by mining activities have become more serious and urgently need a reexamination of mineral resource exploitation mode [26,32]. Based on demands for efficient economic, virtuous ecological circle, increasing resource efficiency, the mineral resources exploitation in the future should be the sustainable socioeconomic development in orientation [12,24], and its essence is a harmonious and coordinated development of mineral resources exploitation between human and environment [3,8]. In general, it is a new development model after rethinking and repositioning the relationship of human, resources exploitation, and nature. This is a result that humans get in the quest of rational resource exploitation model.

Intelligentization of mining production is an important part of smart mineral resources exploitation; specifically, the intellectualized process and the sophisticated management of smart mining production can be regarded as a continuation and development of "mining informatization" and "digital mine". Knowledge-based and intelligence techniques are increasingly introduced into mineral resources extraction. Along with the advancement of mine information process, mining production management becomes more and more complicated. Consequently, systems in the aspects of mining planning, mining construction, daily production management and service will put forward more higher requirements for innovative information technologies. In order to improve the ability of mining production management and rapid adaptability to the future changes, apparently, this need to establish a set of intellectualized information system integrating production management, emergency command, environmental protection, etc., which covers mining production, mine safety, intelligent scheduling, intelligent decision, etc. The construction of smart mining production is not only an inevitable requirement of mine development in the future, but also a strategic choice of mining informatization construction. Hence, how to combine the current status of mineral resources exploitation and mining information level, strengthen the construction and research of intelligent mine, promote a leap-forward development of mineral resources exploitation, and to coordinate mine utilization and environmental protection, is an important opportunity and challenge.

\section{Concept and content of Smart Mine}

Digital mine is a digital project on the basis of mine information database, which makes full use of modern spatial analysis, data acquisition, knowledge discovery, virtual reality, network, multimedia and scientific computing technology. In addition, it provides a new technology platform to support the analogy, simulation and process analysis for mineral resources evaluation, mining planning, design, production safety, decision-making and management [25,27,29]. With the advancement of mine informatization, the meaning of digital mine has gradually expanded and now the concept of digital mine is the main focus. The appearance of smart engineering means a tendency different from digital engineering [6]. Smart Mine makes full use of the current information technologies, including more thorough cognitive technology, more extensive interconnection technology and further intellectualized technology, which makes the mineral resource exploitation more effective and smarter in order to achieve the objectives of cost-effective, virtuous ecological circle, increasing resource efficiency. Smart Mine doesn't focus on the individual mine information technology application in mineral resources utilization; instead, it regards mining production process as an integrated whole. Information technologies are applied comprehensively and systematically to all links such as product exploitation and environmental protection, etc. Therefore, we think that the concept of Smart Mine engineering mainly consists of three important dimensions. First, people need and are able to perceive and measure the nature and changes of mine exploitation more thoroughly. Second, the whole process of mine utilization is more comprehensively interconnecting. Third, on this basis, all the things, processes, operation modes have deeper intellectualization; people can obtain more intellectualized insight on mine exploitation.

As derived from the above, "digital" represents information and information service and "smart" represents intelligence and automation. Digital engineering takes information resource application as center; whereas, Smart Mine takes automated intelligent application as center (Figure 1). Though both have relevance and intersection, different tendentiousness is obvious. To sum up, "Smart Mine" generally has four major characteristics: 


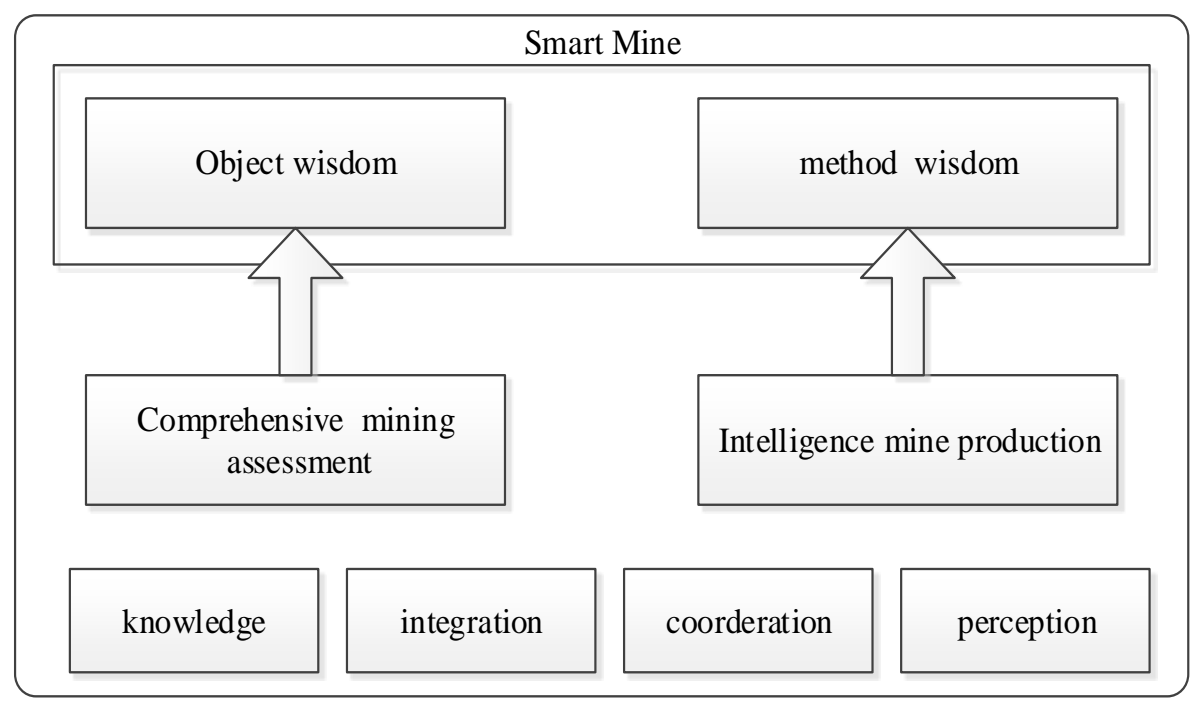

Figure 1. Connotation of Smart Mine

- Perception - monitoring, computing and analysis through the ubiquitous sensing and intelligence facilities.

- Integration - the "internet of things" fully integrates with mine monitoring network, which provides an intelligent infrastructure.

- Coordination - based on intelligent infrastructure, all key systems and participants of mine cooperate with each other harmoniously and efficiently, forming the best status of mining production.

- Knowledge - enterprises and individuals employ various types of knowledge on intelligent facilities, providing intelligent support for the mine.

From the above features, "Smart Mine" is making more "intelligent" communication among people, mines, society and nature, so that the mining production systems become more "intelligent ". For this purpose, Smart Mine focuses on not only resources exploitation, but also the balance and coordination in the mineral resource utilization process.

\section{Architecture of Smart Mine}

Smart Mine needs knowledge-based smart framework, which commonly includes three layers (Figure 2). First, the internet of things as the fundamental equipment layer. This level is the nerve endings of Smart Mine, including different kinds of sensor nodes, RFID, PDA, monitor terminals, etc. Second, the network layer that includes sensor networks, grid and cloud computing networks, internet, etc. Third, the application layer, which orients to collection, management and application of spatial data, video and audio multimedia data, and various types of thematic data. It deals with intellectualized device control, intelligent management and service, intelligent decision-making, etc.

Compared with previous technologies used in mining informatization and digital mine, Smart Mine involves various new technologies, which basically have two novel technologies: sensor network technology based on the internet of things used in mining perception, and knowledge engineering technology used in mining production system.

\subsection{Mine sensor network}

The internet of things as the key technology is the core component in the innovative ideas of "Smart Mine". The internet of things technology [7,22] includes extensive communication and information exchange between Machine-to-Machine (M2M), machine-to-people (M2P), people-to-people (P2P) and people-to-machine (P2M)), which combines all kinds of information sensing equipment in the mining production processes such as RFID, infrared sensors, positioning system, laser scanner and other devices, forming a huge sensor network [28], or a cyber-physical systems [11]. Its purpose is to let all devices, products and networks connect together, provide more wisdom management styles and deeper insights for managers through a real-time dynamic sensory information acquisition, transmission and processing.

The application of internet of things technology in ground and underground mining equipment management and technical support can achieve the types, status, quantity, and distribution of equipment in the aspects of digitization, visualization, networking, and greatly improve the precise support level of mining production. For this reason, by taking full advantage of internet of things technology, we can actively enhance equipment management level, raise the ability of 
technical security support system and advance the "internet of things of mine" construction. Thus, this requires to strengthen standard formulation of "internet of things" for mining enterprises, vigorously promote mine "internet of things" construction and automation equipment application in the mine exploitation, continuously improve the standards of "intelligentization" and mine equipment automation in the link of storage, usage, repair and management, gradually realize intellectualization of production, detection, repair, storage and supply, management techniques, and comprehensively enhance the overall performance of mining equipment support.

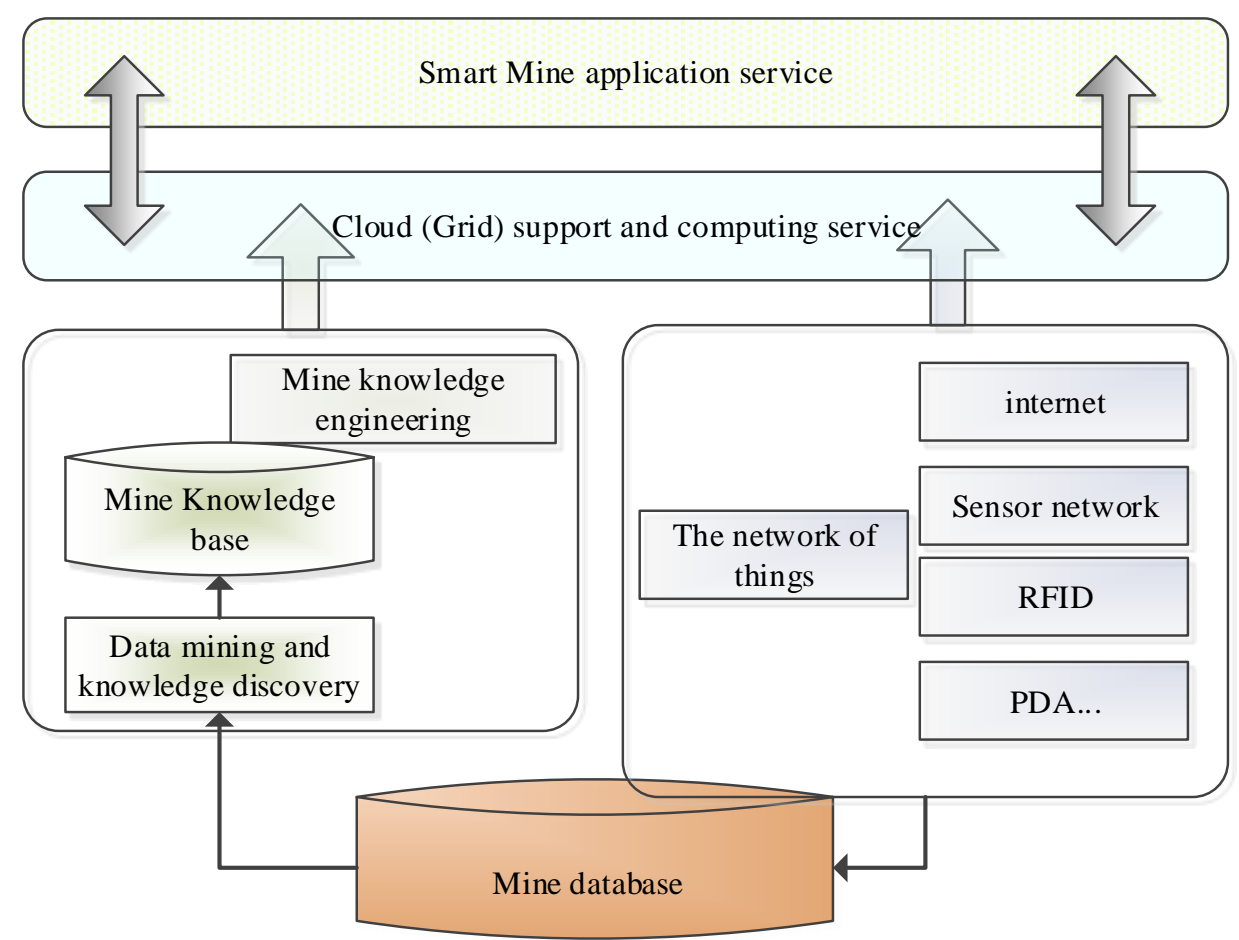

Figure 2. Architecture of Smart Mine

\subsection{Mining knowledge engineering}

Mining intelligence, also called mining production intelligence, is usually understood as a way that knowledge can be generated from data and information in mining production processes, which helps mining enterprises make wise decisions [19]. These data include spatial data, non-spatial data, geological data, mining data, ventilation data and drainage data etc. The key focus of mining intelligence is to extract usable data from production management system and clean up the data. Then, after the extract-transform-load (ETL) process, merge them into an enterprise-level mining data warehouse, thus obtain a global view of enterprise-level data. Analyze them using appropriate query and analysis tools, data mining tools, or on-line analytical processing (OLAP) tools [14,15], and provide knowledge-support for managers in the decision-making process.

The process of knowledge service in mine knowledge engineering is as the following (Figure 3).

- The problem items are extracted from users' query statements, and the mine knowledge service system has an ability to parse and define the problems.

- The problem items are parsed and the concepts and the relationships are extracted.

- The concepts and relationships of the mining process are mapped to the domain ontology. The domain ontology base is to acquire, describe and represent knowledge in mining product fields, and provide concepts and relationships in mining field with the help of mining experts.

- The knowledge items related to the problems is obtained by the concept reasoning employed domain ontology of mining production process; the appropriate knowledge items are extracted combined with the knowledge management strategy of mining production process.

- The knowledge items are pushed to the users through the knowledge push function to make decisions for the mine production management. 
Mining knowledge engineering is the core of intelligent mining production system. It contains two types of knowled ge. One is obtained via transformation, sorting, interpretation, acquiring, representation and processing of various mine data; the work involves mining knowledge acquisition, representation, processing, discovery and excavation in mining production process, and it is the basic problem in mining intelligence research. Another is required for production process intellectualization. This is where unsolved problems remain in mining knowledge engineering. Only completely implementing mining knowledge engineering can the mining production can be smarter and wiser.

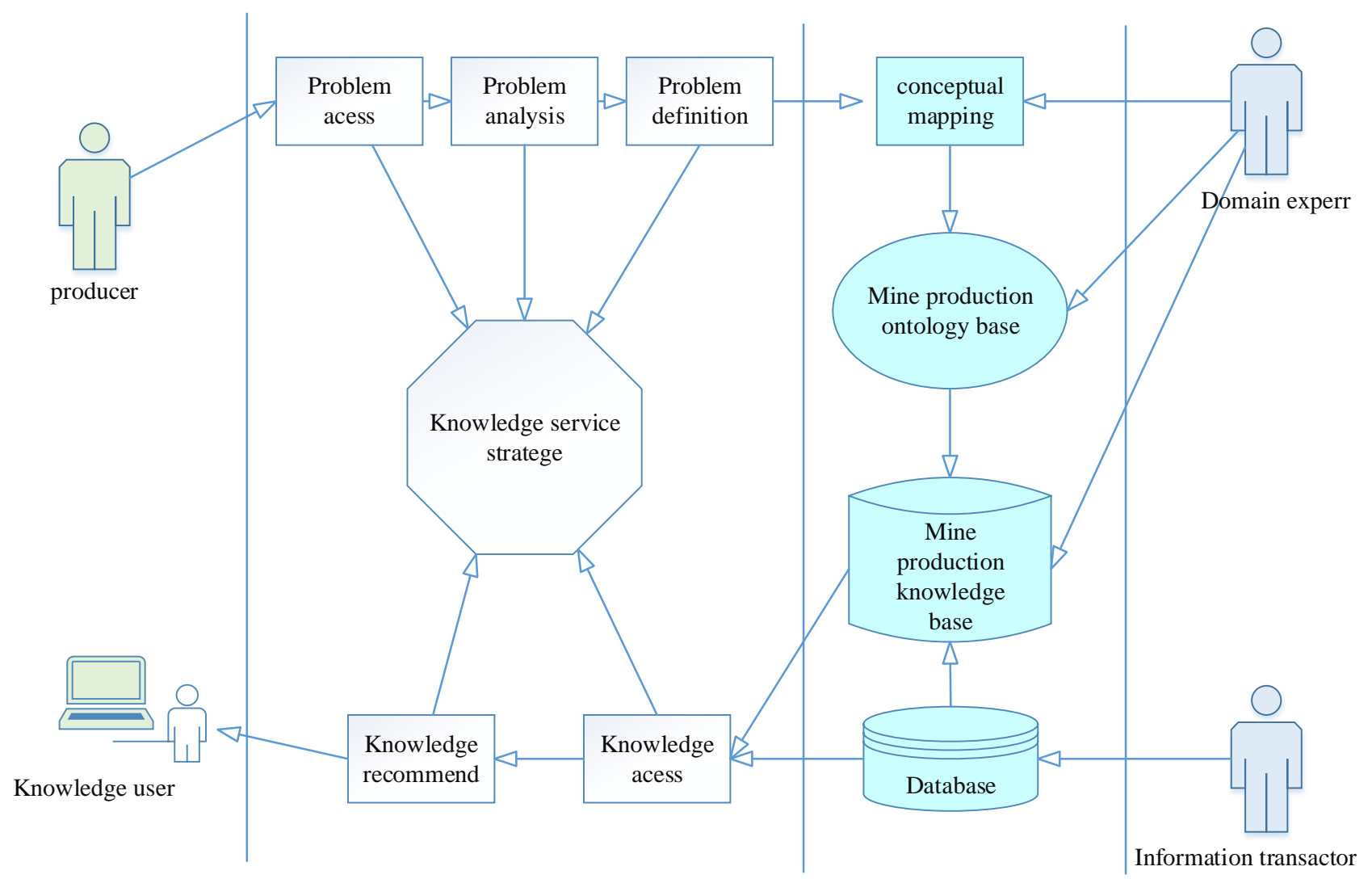

Figure 3. Knowledge service in Smart Mine

\section{The main content of Smart Mine construction}

\subsection{The supporting network of mine information flow and material flow}

The network in mining production system is a carrier that converges and coordinates distributed intelligence cooperation, which associates all sorts of dispersed resources (include information resource and knowledge resource) with human activities as a nervous system and makes the dispersive system forming an intelligent whole. Without the unified network underlying platform, decentralized information can't form a whole. The supporting network of information flow and material flow gathers various available resources and promotes efficiency of all the mining information resources' performance, by which the dispersed local wisdom and ability can be organized as a unified cooperation body. Individual intelligence could only be operated on single system or platform. With various system intelligences, the whole intelligence corporately runs by connecting with each other using supporting network. So, mine network of material and information is a converging tool to run the distribution intelligences.

\subsubsection{The supporting network of mine material flow}

Typifying an efficient integrity of "perception", "fusion" and "decision", "Smart Mine" is considered a structure model of mining intelligent production management system. New valuable information is drawn from the mining production perceptual system by the analysis, judgment, comparison and integration of information, so that mine managers can make decisions more sensible. Therefore, the construction of sensing network in the Smart Mine should focus on "mine perception". For the present mining enterprises, it needs to build a centralized sensor network that integrates scheduling video systems, early security warning system, mine sensing system, underground personnel positioning system, mine 
equipment positioning and monitoring system, materials management and positioning visualization system and other resources. This way, a centralized architecture can be realized for the construction goals of mining entity infrastructure and information infrastructure convergence.

\subsubsection{Basic platform of mine spatial information resources}

The sharing platform construction of mine spatial information resources should consider the practical requirements of mine spatial information sharing applications and construction situation of the existing mine spatial information. On the basis of actual investigation and full demand analysis, the construction is supposed to abide the flowing principle: "long-term planning, advanced and practical, resource reuse, and saving investment", and adopts service oriented architecture (SOA) based on Service GIS technology and other technologies, which will realize the integration, sharing and full use of the scattered multi-source mine spatial information resources to build a mine geographical information sharing service center and provide a spatial information infrastructure for mine resource exploitation.

Serving as an important supporting technology of "Smart Mine", information sharing service is oriented to service mode which take all the resources, data and applications of information as network service to various mine users. Therefore, it is the key to realize the "deeper intellectualization" objective in Smart Mine.

In mining field, network sharing service can promote information fusion and provide the on-demand service information requirements for different departments, which can effectively meet the need of timely accessing mine information, scientific decision-making and efficiently implementing mission for managerial personnel. In other words, it has an important support to multidimensional information perception, multiple information fusion, intellectualized production command and decision-making, and information resource sharing.

\subsection{D ground and underground information management}

To fully perceive mines, we need all-round perception about the space of mineral resources exploitation including ground and underground space [30]. This perception should comprehensively considerate various problems such as representation and display of spatial data in mining zone. Therefore, it is essential to synthetically use geographic information system technology, multimedia technology, human ergonomics and safety system knowledge to form a 3D spatial information system accorded with human cognitive laws; that is, a 3D visualization contrast between ground and underground (Figure 4). Then, using actual mineral exploitation data by virtual reality technology and various solid modeling technologies, the system is to build a 3D visualization application, which should have functions such as real-time monitor data display and browse, and various parameters query and real-time status information retrieval of mine equipment.
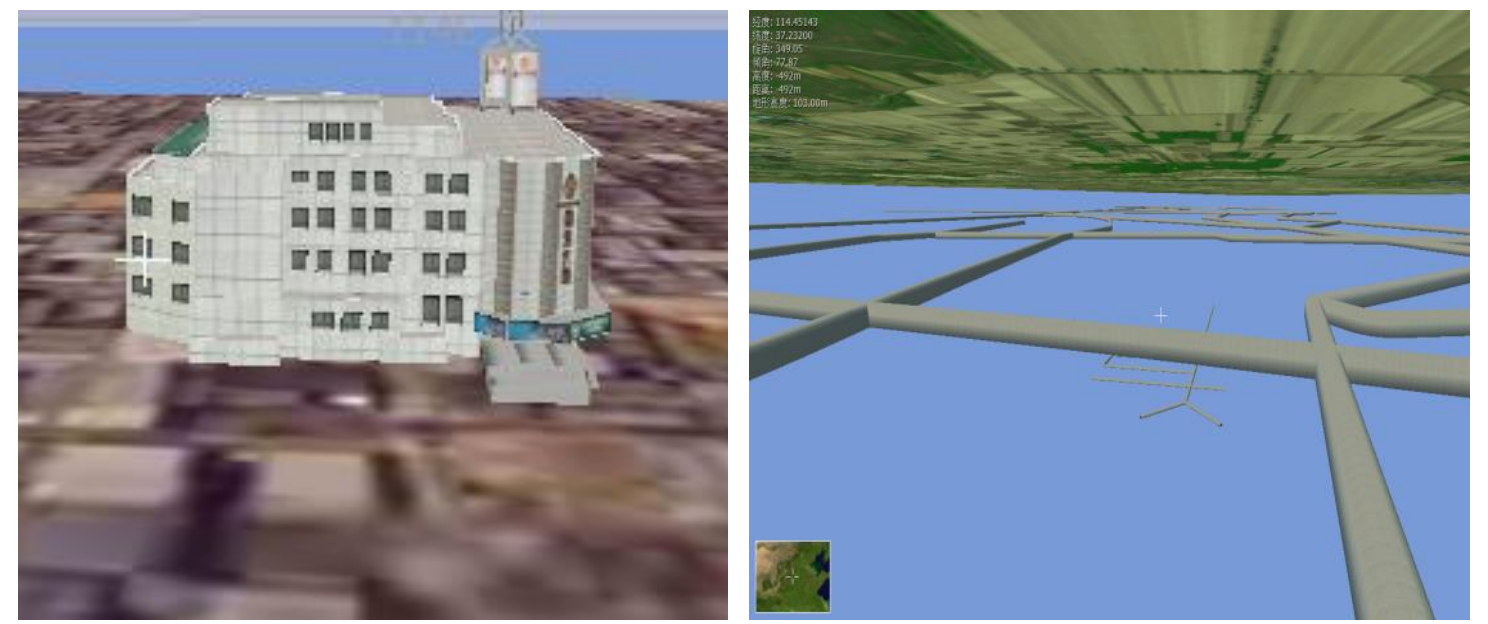

Figure 4. 3D Ground and Underground Contrast System.

\subsection{The collaborative and intellectualized mining production}

The mining informatizational construction that takes data, information and system construction as the center is gradually giving way to collaborative and intellectualized system construction. The concept of Smart Mine production system emphasizes the integrity of sensors, intelligence and wisdom. The basic tendency is to build intelligent network environment of mining production system and improve mining production effectiveness by more automated network services. Mining 
production system in Smart Mine will be able to collect data and extract knowledge from data intelligently, which will then help us make better decisions. To make the whole process of mineral resources exploitation wiser, there must be more intelligent planning, intellectualized risk awareness, implementation and analysis using all available technologies mentioned above.

\subsection{Harmonious and sustainable mineral resources exploitation mode between human and environment}

The notion Smart Mine embodies a harmonious and sustainable development mode between human and environment. In the process of mining production, we should not only consider the mineral resources utilization and ecosystem restoration, but also pay attention to ecological balance and harmony between man and the nature environment in the long run. Sustainable exploitation mode of mineral resources contains dual meaning of intelligence. One is tool intelligence, which uses intellectualized technology, improves the intellectualization of whole production process and management. Another is target intelligence, that helps us grasp the future direction of our activities by a correct evaluation ability: choose more valuable intelligent decisions under the consideration of economy, society and environment factors by analysis, reasoning, judgment, thinking and decision-making. Tools intelligence and target intelligence are unified, which contributes to the construction of Smart Mine.

\section{Conclusions}

Smart Mine provides new power for future mine exploitation and also puts forward new challenges to the existing mining enterprises. This is a long-term goal; the important thing is the construction process in which we ought to focus on knowledge engineering during the course of mine supporting network construction employed by the Internet of Things. On this basis, we can manage the production and exploitation process with a more delicate and dynamic way to achieve the "intelligent" status. Only in this way can we use mineral resource on the base of resources utilization and environment selfpurification, and actively reduce resource consumption and decrease pollution. At the same time, we can raise resource utilization and productivity level, and better the relationship between man and the nature in the process of mineral resources exploitation.

\section{Acknowledgements}

This work was supported by a grant from the National Natural Science Funds Fund (41572341), National Key Research and Development Program of China (2016YFC0803103).

\section{References}

1. S. Azad, "Environmental Degradation due to Coal Mining in Baluchistan," Polish Journal of Environmental Studies, vol. 24, pp. 1855-1861, 2015.

2. R. J. Batterham, "The Mine of the Future - Even More Sustainable," Minerals Engineering, vol. 107, pp. 2-7, 2017.

3. F. Bian, "Principle and Methods of Digital Engineering (second edition) ", Surveying press, 2011.

4. C. F. Calvillo, A. Sanchez-Miralles and J. Villar, "Energy Management and Planning in Smart Cities," Renewable \& Sustainable Energy Reviews, vol. 55, pp. 273-287, 2016.

5. A. Fernandez-Ares, A. M. Mora, M. G. Arenas, P. Garcia-Sanchez, G. Romero, V. Rivas, P. A. Castillo, and J. J. Merelo, "Studying Real Traffic and Mobility Scenarios for a Smart City Using a New Monitoring and Tracking System," Future Generation Computer Systems-the International Journal of Escience, vol. 76, pp. 163-179, 2017.

6. X. S. Ge, Y. M. Zhang, "From Digital Mine to Smart Mine," Key Engineering Materials, vol. 480-481, pp. 1607-1612, 2011.

7. N. Gershenfeld, R. Krikorian, and D. Cohen, "the Internet of Things," J. Scientific American, vol. 291 (4), pp. 76-81, 2004.

8. A. Gore, "The Digital Earth: Understanding our planet in the 21st Century," http://portal.opengeospatial.org/files/?artifact_id=6210, 2009.

9. R. Jeremy, "Mining, Society, and a Sustainable World," Springer-Verlag Berlin and Heidelberg GmbH \& Co. K, 2009.

10. E. Lebre, G. D. Corder and A. Golev, "Sustainable Practices in the Management of Mining Waste: A Focus on the Mineral Resource," Minerals Engineering, vol. 107, pp. 34-42, 2017.

11. E. A. Lee, "The Past, Present and Future of Cyber-Physical Systems: A Focus on Models," Sensors, vol. 15, pp. 4837-4869, 2015.

12. C. Li, A. Wang, X. Chen, Q. Chen, Y. Zhang, and Y. Li, "Regional Distribution and Sustainable Development Strategy of Mineral Resources in China," Chinese Geographical Science, vol. 23, pp. 470-481, 2013.

13. D. Li, "Perspective for Smart Factory in Petrochemical Industry," Computers \& Chemical Engineering, vol. 91, pp. 136-148, 2016

14. J. L. Lu, X. L. Wang, L. Ma and A. X. Zhao "Informationization of Coal Enterprises and Digital Mine," J. Coal Science and Engineering, vol. 14(3), pp. 512-516, 2008. 
15. O. Marban, J. Segovia, E. Menasalvas and C. Fernandez-Baizan, "Toward data mining engineering: A software engineering approach," J. Information Systems, vol. 34(1), pp. 87-107, 2009.

16. P. Masek, J. Masek, P. Frantik, R. Fujdiak, A. Ometov, J. Hosek, S. Andreev, P. Mlynek, and J. Misurec, "A Harmonized Perspective on Transportation Management in Smart Cities: The Novel IoT-Driven Environment for Road Traffic Modeling.," Sensors (Basel, Switzerland), vol. 16, 2016.

17. S. Mhlongo, P. T. Mativenga and A. Marnewick, "Water Quality in a Mining and Water-Stressed Region," Journal of Cleaner Production, vol. 171, pp. 446-456, 2018.

18. J. M. Nikolic, D. Vasovic, G. Janackovic, A. I. Petkovic, and I. I. Krstic, "Improving the Management System of Mining and Energy Complexes Based on Risk Assessment, Environmental Law and Principles of Sustainable Development," Journal of Environmental Protection and Ecology, vol. 17, pp. 1066-1075, 2016.

19. I. O. Osunmakinde, "Towards Safety from Toxic Gases in Underground Mines Using Wireless Sensor Networks and Ambient Intelligence," International Journal of Distributed Sensor Networks, Vol. 9, pp. 1-15, 2013

20. B. Pandey, M. Agrawal and S. Singh, "Assessment of Air Pollution Around Coal Mining Area: Emphasizing on Spatial Distributions, Seasonal Variations and Heavy Metals, Using Cluster and Principal Component Analysis," Atmospheric Pollution Research, vol. 5, pp. 79-86, 2014.

21. V. Rimondi, J. E. Gray, P. Costagliola, O. Vaselli, and P. Lattanzi, "Concentration, Distribution, and Translocation of Mercury and Methylmercury in Mine-Waste, Sediment, Soil, Water, and Fish Collected Near the Abbadia San Salvatore Mercury Mine, Monte Amiata District, Italy," Science of the Total Environment, vol. 414, pp. 318-327, 2012.

22. J. A. Stankovic, "Research Directions for the Internet of Things," IEEE Internet of Things Journal, vol. 1, pp. 3-9, 2014.

23. Y. Sun, C. Yan, Y. Wei, H. Xu, and Y. Yao, "Influence of Topsoil Addition on Species Diversity and Aboveground Biomass of Plant Community on the Damaged Mined Land in Altay, China," Fresenius Environmental Bulletin, vol. 26, pp. 2214-2220, 2017.

24. Z. Simkova, M. Cehlar and H. Pavolova, "Strategy of Point out Relevance of Responsible Exploitation of Mineral Resources," ACTA Montanistica Slovaca, vol. 21, pp. 208-216, 2016.

25. J. P. Vasseur, and A. Dunkels, " Smart Cities and Urban, in Networks Interconnecting Smart Objects with IP, in the Next Internet ", Morgan Kaufmann, 2010, pp. 335-351.

26. J. P. R. De Villiers, "How to Sustain Mineral Resources: Beneficiation and Mineral Engineering Opportunities," Elements, vol. 13, pp. 307-312, 2017.

27. L. G. Wang, and X. Chen, "Advancing Technologies for Digital Mine," The Chinese Journal of Nonferrous Metals, vol. 26, pp. $1693-1710,2016$.

28. Q. Wang and Y. Feng, "The Development of Internet of Things in Coal Mine Based on Rough Set," AISS, vol. 4, pp. 152 - 159, 2012.

29. L. Wu, "Progress of Digital Mine in China," J. Geoinformatic World, pp. 7-13, 2008.

30. Q. Wu and H. Xu, "Three-dimensional Geological Modeling and its Application in Digital Mine," Science China-Earth Sciences, vol. 57, pp. 491-502, 2014.

31. X. Zhang, S. H. Chan, H. K. Ho, S. Tan, M. Li, G. Li, J. Li, and Z. Feng, "Towards a Smart Energy Network: the Roles of Fuel/Electrolysis Cells and Technological Perspectives," International Journal of Hydrogen Energy, vol. 40, pp. 6866-6919, 2015.

32. X. Zhang, L. Yang, Y. Li, H. Li, W. Wang, and B. Ye, "Impacts of Lead/Zinc Mining and Smelting on the Environment and Human Health in China," Environmental Monitoring and Assessment, vol. 184, pp. 2261-2273, 2012.

33. A. Zanella, N. Bui, A. Castellani, L. Vangelista, and M. Zorzi, "Internet of Things for Smart Cities," IEEE Internet of Things Journal, vol. 1, pp. 22-32, 2014.

Xiaosan Ge received the Bachelor degree from Henan Polytechnic University, Jiaozuo, China, in 1994, the Master degree from Henan Polytechnic University, Jiaozuo, China, in 2004, and the Ph.D. degree from Wuhan University, Wuhan, China, in 2007. He worked at Henan Geomatics Centre, as the Vice - Chief Engineer from 2013 to 2014. Now he is working as associate professor and Master's Supervisor at Key Laboratory of Mine Spatial Information Technologies of National Administration of Surveying, Mapping and Geoinformation, Henan Polytechnic University. His research interests include spatial information service, mine spatial information resource sharing, smart mine and geographic knowledge engineering.

Shuai Su is a postgraduate student at Key Laboratory of Mine Spatial Information Technologies of National Administration of Surveying, Mapping and Geoinformation, Henan Polytechnic University. His current research interests include spatial information service and spatial information analysis.

Haiyang $\mathbf{Y u}$ is an associate professor at Key Laboratory of Mine Spatial Information Technologies of National Administration of Surveying, Mapping and Geoinformation, Henan Polytechnic University. His research interests include remote sensing theory and application, laser radar data processing and application.

Gang Chen is a professor at Key Laboratory of Mine Spatial Information Technologies of National Administration of Surveying, Mapping and Geoinformation, Henan Polytechnic University. His research interests include geographic information theory and method, $3 \mathrm{~S}$ integration, digital city, digital mine. 
Xiaoping $\mathbf{L u}$ is a professor and doctoral supervisor at Key Laboratory of Mine Spatial Information Technologies of National Administration of Surveying, Mapping and Geoinformation, Henan Polytechnic University. His research interests include photogrammetry and remote sensing, digital mine. 